\title{
Gender and race differences in the correlation between body mass and education in the 1971-1975 NHANES I
}

\author{
J Paul Leigh, James F Fries, Helen B Hubert
}

\begin{abstract}
Study objective-Differences in the correlation between body mass index and education across four gender and race groups were investigated while simultaneously accounting for occupation, income, marital status, and age.

Design-The study used analysis of covariance techniques to calculate average body mass and confidence intervals within education categories while simultaneously adjusting for the covariates: age, square of age, family income, marital status, and occupation.
\end{abstract}

Setting-Data were drawn from the US National Health and Nutrition Examination Survey (NHANES I), 1971-1975. NHANES I is a national probability sample designed to gather information on the non-institutionalised US civilians, ages 1-74 years.

Subjects-Samples of 8211 white women, 1673 black women, 6188 white men, and 1023 black men were drawn from the NHANES $I$, 1971-1975.

Main results-Data in the female samples indicate a strictly inverse relation between body mass and years of schooling among white women and an inverted " $U$ " association among black women, achieving a maximum around 8 to 11 years of schooling. In the male samples data indicate inverted "U" relations among both black and white men, reaching maxima between 12 and 15 years of schooling. The sides of the "U" curve are much steeper for black than for white men.

Conclusions-The four gender/race categories display four different body mass index and education associations. These four associations are only slightly altered by simultaneously adjusting for two additional measures of socioeconomic status: occupation and income.

Department of Economics, San Jose State University, San Jose, CA 95192-0144, USA

J P Leigh

Department of

Medicine, Stanford

University School of Medicine, Stanford,

CA, USA

J F Fries

H B Hubert

Correspondence to: Dr Leigh

Accepted for publication July 1991

Obesity has been strongly linked to heart disease, ${ }^{1}$ many forms of cancer, ${ }^{2}$ and arthritis, especially of the knees. ${ }^{3}$ Thus further research into the causes and/or correlates of obesity is warranted. This study investigates the correlation between education, one of the components of socioeconomic status, and obesity in a national sample of adult women and men. Prior research indicates that socioeconomic status measured in a variety of ways is strongly and inversely correlated with being overweight among women. ${ }^{4-10}$ The results studies find a negative relationship, ${ }^{4}$ while others find a weak positive association, ${ }^{5}$ and still others find a curvilinear relationship. ${ }^{6}$ A recent review of published reports confirms the inverse relationship for women and the great variety of findings for men. ${ }^{8}$ However, these previous studies (1) do not usually account for additional suspected correlates of body mass such as marital status and square of age, (2) do not rely on a model which accounts for the separate influences of occupation, income, and education, and (3) do not allow for curvilinear relations between schooling and body mass.

An important criticism of prior research on socioeconomic correlates of obesity is that the studies have not carefully distinguished between social science variables. Occupation, income, and education are either grouped together to form a socioeconomic status index or treated separately in univariate analyses. Neither approach is fully satisfactory. Occupation, income, and education are best viewed as separate variables for two reasons. First, they have different implications for government and business intervention. ${ }^{11} 12$ For example, some businesses might sponsor exercise or health promotion campaigns at work. Income can be adjusted through businesses raising wages or government altering taxation, welfare, and social security spending. Education may be affected by government spending on schools, Headstart, and special training programs such as the Job Corps. An economic analysis in a widely cited text by Feldstein ${ }^{13}$ suggests that if increased education improves health, then national spending on education may be more cost-effective than spending on medical care to reduce national mortality and morbidity. Second, there are widely accepted theories explaining relationships among occupation, income, and education. A proper understanding of the role of schooling, for example, must take into account that for most people, educational achievement precedes career choice and subsequent income. Thus many social science models assume that high educational achievement results in high earnings and employment in "good" jobs rather than vice versa. "1 among men have been less consistent. Some

\section{Methods}

SAMPLE

Data were drawn from the medical examination component of the first US National Health and Nutrition Examination Survey, 1971-1975 (NHANES I), conducted by the National Center for Health Statistics. NHANES I was a multistage stratified probability sample of clusters of persons in land based segments and is represen- 
tative of the civilian non-institutionalised population then residing in 48 states. ${ }^{14}$

Since our interest was among adults, persons under 21 were excluded from the analyses. The subsample consisted of 8211 white women, 1673 black women, 1023 black men, and 6188 white men. Persons of other races were excluded due to small sample sizes.

\section{VARIABLES}

The dependent variable was body mass index calculated as weight $(\mathrm{kg})$ divided by height $(\mathrm{m})$ squared ( $=$ weight $/$ height $^{2}$ ). Independent variables included years of schooling completed, age, age squared, married spouse present, separated, divorced, widowed, never married, family income, work/activity status including binary variables for retired, student, disabled, homemaker and/or unemployed, and employment variables for professional, manager, sales worker, craftworker, operative, labourer, farmer, and service worker. Income was entered in categories in the NHANES I. The income variable we used represented midpoint values within each category. Thus, for example, income between $\$ 2000$ and $\$ 3000$ was recorded as $\$ 2500$. Table I provides a summary of and descriptive statistics on variables used in the analyses.

\section{ANALYSES}

Analyses of covariance and multiple regression techniques were used where body mass index was treated as the dependent variable, and five categories of schooling, age, age squared, income, seven occupations, three marital status categories, and work/activity status variables were treated as covariates. Separate regressions were run for women and men since prior studies showed great disparities across gender in the correlation between body mass and schooling. ${ }^{4-10}$ The five schooling categories were: 0 to 7 years, 8 to 11 years, 12 years, 13 to 15 years, and 16 and over.
The first category, 0 to 7, corresponds to grammar or elementary school in the US; 8 to 11 corresponds to some high school; 12 implies a high school diploma; 13 to 15 corresponds to some college; and 16 and over means a completed college education or more. Age and marital status categories are widely recognised covariates of obesity. ${ }^{4-10}$ Occupation, income, and activity, eg, retired, student, disabled, and homemaker, are all known to be strongly correlated with education. ${ }^{15-17}$

Two different analyses of covariance were conducted on each of the four gender/race groups. The first included the five schooling categories together with age, age squared, and marital status (columns 1 and 3 in tables II and III). The second included the five schooling categories and all known confounding variables: age through work/ activity status (columns 2 and 4 in tables II and III). These analyses allowed for comparisons between schooling-body mass index relationships which did not control for the well known associations among education, occupation, income, and work/activity status.

In addition, two different sets of weighted multiple regressions were applied. The first weighted multiple regression set treated the five schooling categories as dummy variables (this is equivalent to analysis of covariance). ${ }^{18}$ The second multiple regression approach treated schooling as a continuous variable. Again, two regressions in each set were run within each gender/race category, as described above. The weighted multiple regression techniques were used since NHANES I is a stratified and clustered sample. Unweighted multiple regressions may result in inefficient parameter estimates and biased standard errors since the regression errors within strata and groups are often correlated. ${ }^{19} \mathrm{To}$ estimated regressions properly for this sample, the weighted multiple regression routines available in PCCARP were used. ${ }^{20}$

\section{Results}

Weighted and unweighted analysis of covariance and multiple regressions yielded similar results. The potential bias from using a stratified and clustered sample appeared minimal in these analyses of the NHANES I data. Thus the results presented here are for the first and most familiar technique, analysis of covariance.

Tables II and III present the analysis of covariance results for women and men. The first row indicates the mean body mass index for each of the four subsamples. The next five rows present the mean body mass indices, for each of the five schooling categories, together with their $95 \%$ confidence intervals. Two sets of results apply to each of the two analyses of covariance. The first included only a few covariates: age, age squared, and four marital status categories (columns 1 and 3 ). The second included age, age squared, marital status categories, income, seven occupations, and variables for work/activity status (columns 2 and 4 ). In the interest of brevity, only the results pertaining to schooling will be presented and discussed. A longer version of the paper which discusses all results is available from
Service worke

Unemployed

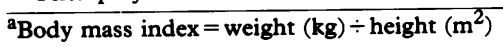
the authors.

$\begin{array}{cccc}00.41 & 00.65 & 21.65 & 22.06 \\ 00.70 & 02.01 & 01.46 & 02.12 \\ 00.88 & 00.40 & 04.62 & 03.37 \\ 54.79 & 58.01 & 0 & 0 \\ 03.72 & 07.41 & 08 \cdot 82 & 11.39 \\ 01.34 & 02.90 & 08.52 & 11.16 \\ 10.60 & 17.12 & 05.18 & 08.92 \\ 00.46 & 00.63 & 09.16 & 15.01 \\ 08.17 & 01.41 & 14.24 & 16.12 \\ 00.46 & 00.29 & 08.36 & 03.00 \\ 00.83 & 00.70 & 02.05 & 02.46 \\ 13.48 & 06.21 & 06.21 & 02.24 \\ 04.16 & 01.52 & 08.73 & 02.15\end{array}$


WOMEN

The results in table II and for figs 1 and 2 provide contrasting pictures for the body mass indexeducation association between black and white women. With increases in education in the early years, from less than or equal to 7 to between 8 and 11 , body mass index increased in black women. After 8 to 11 years, average body mass index fell for black women. The inverted " $U$ " for black women was most pronounced in analysis of covariance results which did not control for occupation, income, and work/activity. For white women, on the other hand, body mass index continuously fell with increased schooling. This continuous drop for white women is especially clear in the analysis of covariance results which controlled for occupation, income, and work/ activity.

While some of the confidence intervals in figs 1 and 2 overlap with other estimated means, the patterns clearly suggest an inverted " $U$ " for black women and a simple inverse relation for white women, and confidence intervals for the highest means do not overlap with the lowest means. A simple comparison of two overlapping confidence intervals, however, cannot test for the overall pattern since information on the three other estimated means and confidence intervals would be ignored. Statistically significant multiple regression results on schooling and schooling squared, both entered as continuous variables, confirmed the upside down " $U$ " for black women

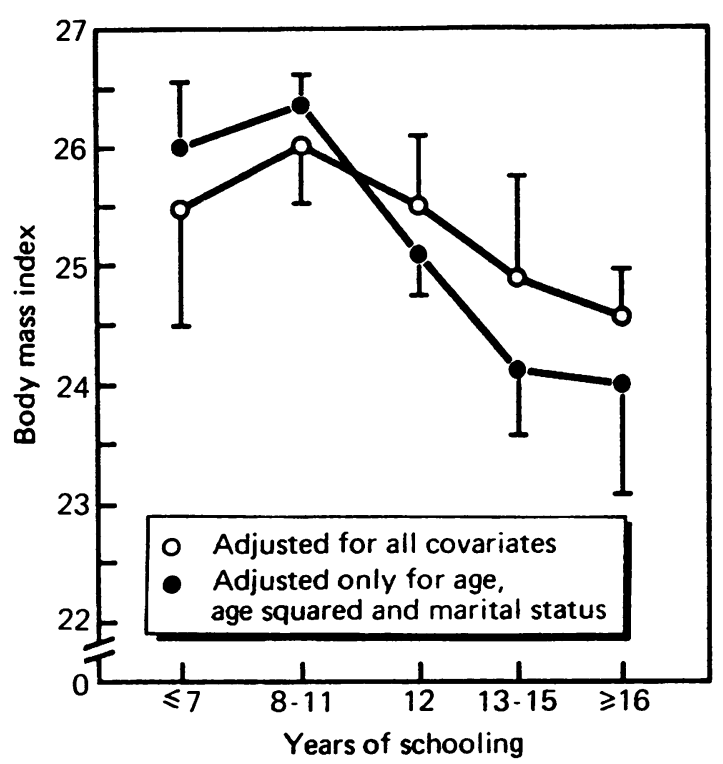

Figure 1 Body mass index and schooling for black women
Table II The relationship between schooling and body mass. index: results of analysis of covariance in women. Dependent variable is body mass index
Table III The relationship between schooling and body mass index: results of analysis of covariance in men. Dependent variable $i$ body mass index

\begin{tabular}{|c|c|c|c|c|c|}
\hline & & \multicolumn{2}{|l|}{ Black women } & \multicolumn{2}{|l|}{ White women } \\
\hline & & 1 & 2 & 3 & 4 \\
\hline Body mass index mean $\left(\mathrm{kg} / \mathrm{m}^{2}\right)$ & & $26 \cdot 364$ & $26 \cdot 364$ & $24 \cdot 469$ & $24 \cdot 469$ \\
\hline School $\leqslant 7$ years & $\begin{array}{l}\text { Mean BMI } \\
(\mathrm{CI})\end{array}$ & $\begin{array}{l}\text { I } 26 \cdot 041 \\
(26 \cdot 597-25 \cdot 389)\end{array}$ & $\begin{array}{l}25 \cdot 529 \\
(26 \cdot 515-23 \cdot 865)\end{array}$ & $\begin{array}{l}25 \cdot 288 \\
(25 \cdot 498-25 \cdot 077)\end{array}$ & $\begin{array}{l}25 \cdot 092 \\
(25 \cdot 455-24 \cdot 829)\end{array}$ \\
\hline $8 \leqslant$ schooling $\leqslant 11$ years & $\begin{array}{l}\text { Mean BMI } \\
(\mathrm{CI})\end{array}$ & $\begin{array}{l}\text { I } \underset{(26 \cdot 315}{26} \\
(282-26 \cdot 040)\end{array}$ & $\begin{array}{l}26 \cdot 084 \\
(26 \cdot 574-25 \cdot 599)\end{array}$ & $\begin{array}{l}25 \cdot 010 \\
(25 \cdot 413-24 \cdot 827)\end{array}$ & $\begin{array}{l}24 \cdot 507 \\
(24 \cdot 846-24 \cdot 168)\end{array}$ \\
\hline Schooling $=12$ years & $\begin{array}{l}\text { Mean BMI } \\
\text { (CI) }\end{array}$ & $\begin{array}{l}\text { I } 25 \cdot 192 \\
(25 \cdot 548-24 \cdot 835)\end{array}$ & $\begin{array}{l}25 \cdot 463 \\
(26 \cdot 055-24 \cdot 171)\end{array}$ & $\begin{array}{l}23 \cdot 801 \\
(24 \cdot 034-23 \cdot 568)\end{array}$ & $\begin{array}{l}24 \cdot 069 \\
(24 \cdot 557-23 \cdot 880)\end{array}$ \\
\hline $13 \leqslant$ schooling $\leqslant 15$ years & $\begin{array}{l}\text { Mean BMI } \\
\text { (CI) }\end{array}$ & I $\begin{array}{l}24 \cdot 157 \\
(24 \cdot 701-23 \cdot 612)\end{array}$ & $\begin{array}{l}24 \cdot 758 \\
(25 \cdot 629-23 \cdot 166)\end{array}$ & $\begin{array}{l}23 \cdot 112 \\
(23 \cdot 354-22 \cdot 870)\end{array}$ & $\begin{array}{l}23 \cdot 488 \\
(23 \cdot 804-23 \cdot 171)\end{array}$ \\
\hline Schooling $\geqslant 16$ years & $\begin{array}{l}\text { Mean BMI } \\
(\mathrm{CI})\end{array}$ & $\begin{array}{l}\text { I } 24 \cdot 017 \\
(24 \cdot 991-23 \cdot 043)\end{array}$ & $\begin{array}{l}24 \cdot 634 \\
(25 \cdot 038-23 \cdot 430)\end{array}$ & $\begin{array}{l}22 \cdot 803 \\
(23 \cdot 082-22 \cdot 524)\end{array}$ & $\begin{array}{l}23 \cdot 000 \\
(23 \cdot 372-22 \cdot 628)\end{array}$ \\
\hline $\begin{array}{l}\text { Additional covariates: } \\
\text { Age, age squared, } 4 \text { marital status categories }\end{array}$ & & Included & Included & Included & Included \\
\hline $\begin{array}{l}\text { Income, } 7 \text { occupations, variables for retired, } \\
\text { students, and unable to work }\end{array}$ & & Excluded & Included & Excluded & Included \\
\hline Sample size & & 1673 & 1673 & 8211 & 8211 \\
\hline
\end{tabular}

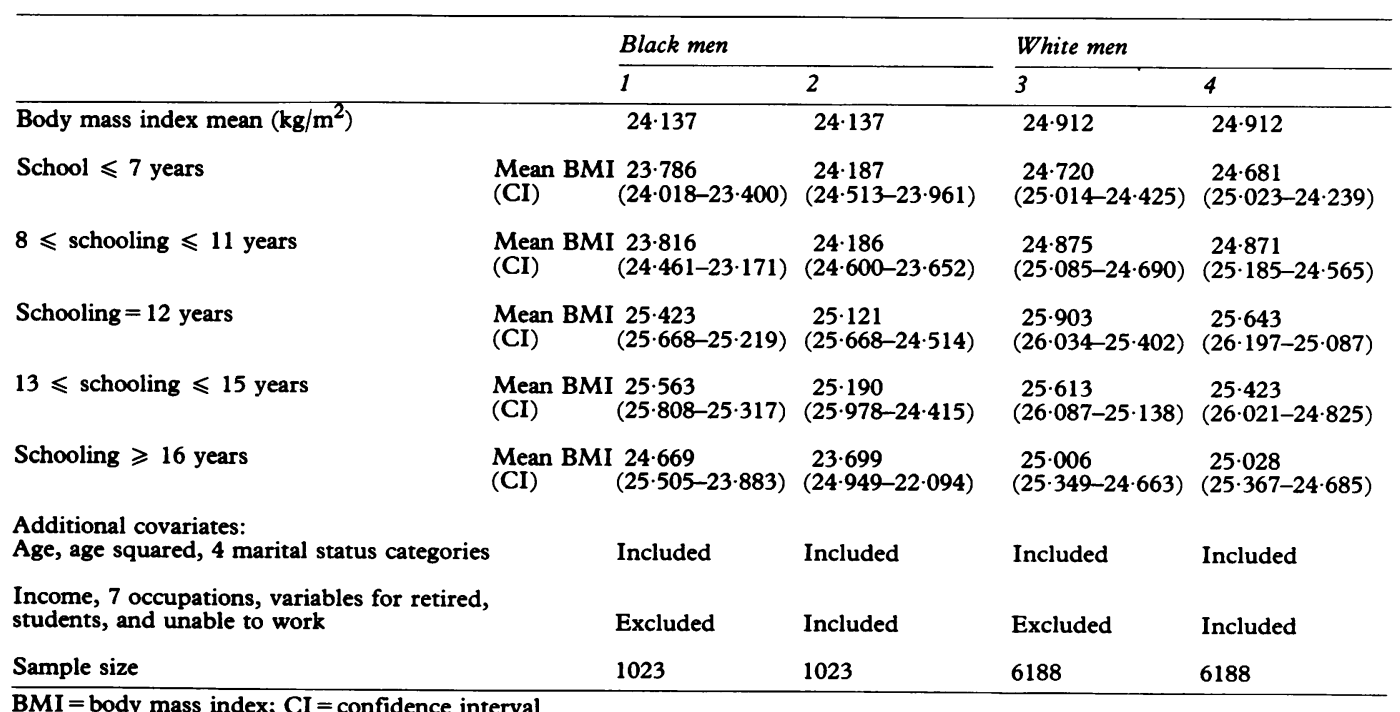


and strictly inverse (monotonically decreasing) relation for white women.

Adjusting for all the covariates appeared to make some difference for both black and white women. The solid and open dots represent estimated means before and after adjusting for income, occupation, and activity. Comparing the lines, it is apparent that adjustment for all

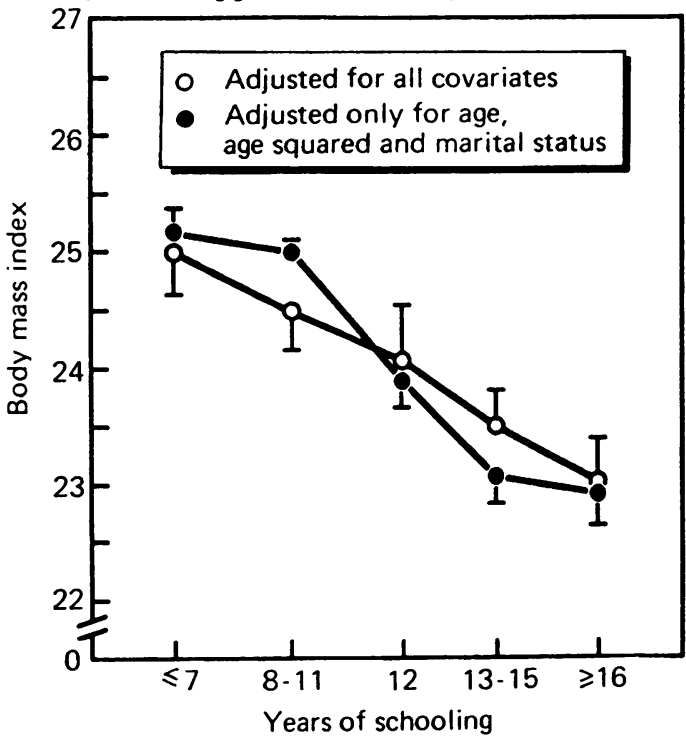

Figure 2 Body mass white women

Figure 3 Body mass index and schooling for black men
Figure 4 Body mass index and schooling for white men
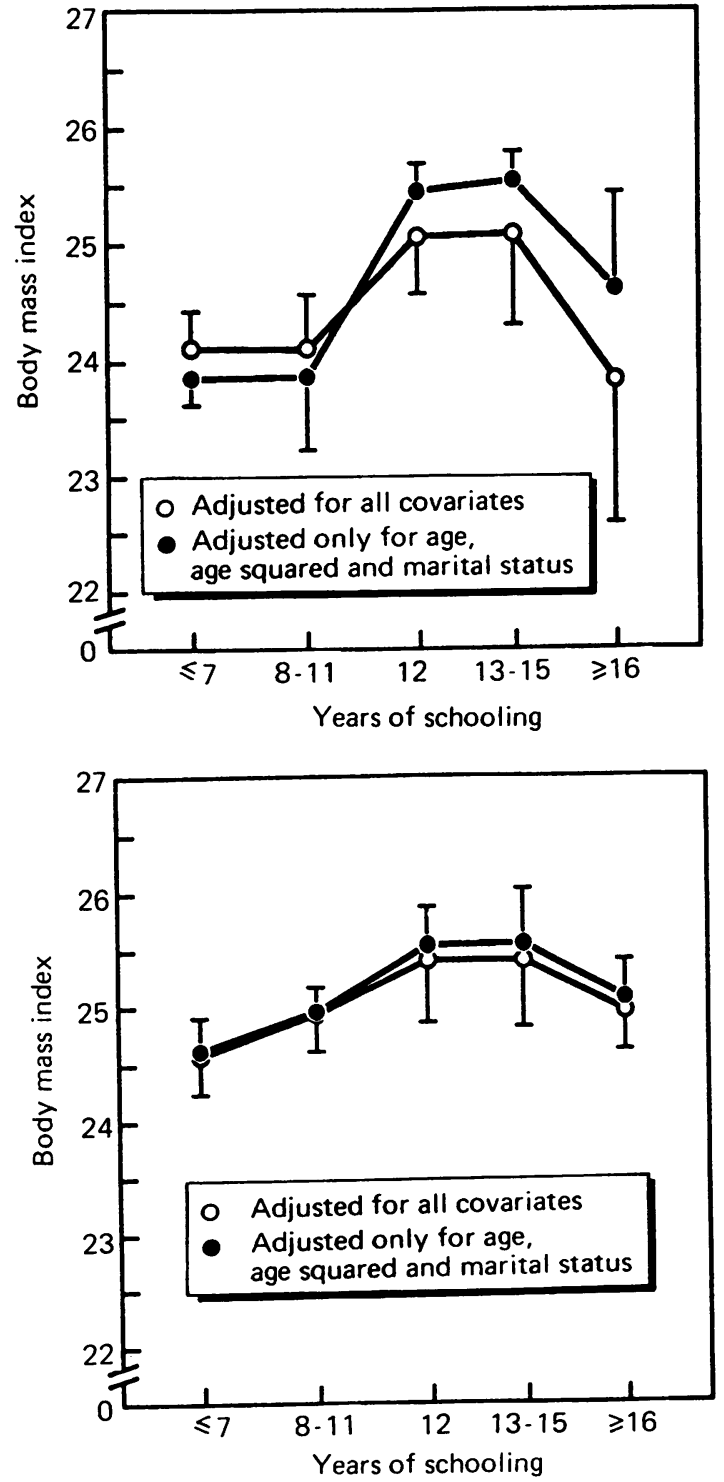

covariates (open dots) weakened the magnitude of the variation in body mass index. Each open dot lies closer to the sample mean body mass index than the corresponding filled dot. The association adjusted for all the covariates for white women (fig 2) suggests a strikingly linear relationship between body mass index and education.

MEN

Results for the men appear in table III and in figs 3 and 4 . Beginning with the 8 to 11 year category, both male figures suggest an inverted " $U$ " shape. The height and magnitude of the inverted " $U$ " vary considerably between the black and white men, however. The black male inverted " $U$ " is tall with steep sides. The white male " $U$ " rises and falls only slightly from the lowest to the highest levels of education. Little variation is present between the first two schooling categories, grammar school and some high school, for black men. The general shape of the associations was only slightly altered once controls are entered for occupation, income, work activity.

\section{Discussion}

The results presented here shed further light on the schooling and occupation debate as it applies to obesity. ${ }^{1121}$ One economic model, the "institutional" theory, would suggest that the schoolingobesity association is indirect ${ }^{21}$; that is, schooling allows access to safe jobs and it is the safe jobs, not the schooling, that lead to better health. The "human capital" view, a second economic model, holds that schooling improves health directly. ${ }^{11}$ Better educated people more efficiently allocate their resources, time, and energy to produce health than less well educated people. In the "human capital" view, schooling has a direct effect on obesity. Additional results from the present study indicate that the broad occupational categories were not statistically significant in their association with obesity while schooling maintained its statistical significance in the four gender/race categories.

A third model, however, cannot be directly tested by these analyses. In this third view, education may act as a surrogate for true causal variables (eg, intelligence, ability to defer gratification, self-efficacy, ambition, drive) which in turn act to increase education level, to decrease body mass, and to obtain a high status job. ${ }^{22}$ In this third interpretation, interventions directed at increasing education levels would not be expected to influence body mass. However, recent research on the association between education on the one hand and blood pressure, disability, and seat belt use on the other ${ }^{122324}$ rejects this view. Our evidence is thus consistent with either the "human capital" or the third, "education as surrogate", view.

The results in table II for women imply that the association of schooling with body mass is different for black compared with white women. Black women with fewer than 7 years of schooling in the 1970s were thinner than black women with between 8 and 11 years of schooling. The low body mass index for black women with fewer than seven years of education may be due to poor health 
and emaciation since lower education level is a risk factor for most chronic diseases. ${ }^{25}$ For white women, the linear inverse association was consistent over the education span.

Perhaps the most controversial findings in tables II and III pertain to the schooling and body mass differences between men and women. An upside down " $U$ " was observed for both black and white men. A strictly linear, inverse relation was observed for white women, and an inverse relation for black women beyond seven years of schooling. While the inverse relation between body mass and socioeconomic status among women is not unique, ${ }^{8}$ the finding of a strictly linear relation with only schooling for white women while simultaneously accounting for the separate influences of income, occupation, and marital status is unique. Prior studies did not control for the separate influences of income, occupation, and marital status.

A number of "human capital" and "education as surrogate" hypotheses are consistent with this finding for white women and black women after eight years of schooling. (1) Schooling has been alleged to teach self discipline, a skill which can be transmitted to dieting and exercise (human capital). ${ }^{15}$ (2) Schooling may improve self efficacy, that is, increase the belief that what happens to a person is their own doing and that luck plays only a small role (human capital). ${ }^{26}$ (3) Alternatively, higher levels of schooling may be achieved by those with greater self efficacy (education as surrogate). The poorly educated may be more likely to have acquired "learned helplessness" than the better educated. Again, if this attitude can be applied to health, more educated women would more likely view their weight as under their control than less educated women. ${ }^{27}$ (4) Schooling may be positively associated with time preferences or delayed gratification (education as surrogate). ${ }^{22}$ More educated women may be more thoughtful concerning the long term health consequences of obesity than less educated women; or those innately possessing low time preference (ability to delay gratification) may thereby achieve higher education levels.

The curvilinear, upside down " $U$ ", relation between body mass and schooling observed for men is intriguing. Prior studies found positive as well as negative relationships. There is no consistency in the prior studies for men as there appears to be for women. ${ }^{8}$ If the relation is, in fact, an inverted " $U$ ", it is not surprising that prior researchers looking for linear relations have been perplexed. If data included mostly men with many years of schooling, a negative relation would be observed. If data were drawn from men with few and many years of schooling, and if a linear model was assumed, a different line with a shallow positive slope would be observed.

The inverted " $U$ " curve for men might be explained by a high body mass being less likely to indicate obesity for men than for women; that is, body mass index may measure other attributes in men, such as muscle mass. Alternatively, if the broad occupation categories do not capture all the variations in working conditions across jobs, then three additional reasons can be suggested: more men than women were employed in physically demanding (fat consuming) jobs in the early 1970s; many of the most physically demanding jobs required only a high school diploma; and men with desk jobs and many years of schooling might have been more likely to exercise than men with desk jobs and few years of schooling. Finally, very little education could have resulted in poor health and subsequent low body mass, especially among black men, similar to what may have been seen in black women.

In conclusion, the four gender/race categories display four different body mass index and education associations. These four associations are only slightly altered by simultaneously adjusting for two additional measures of socioeconomic status: occupation and income. Medical experts frequently advocate government and business interventions designed to improve public health. The strong associations between socioeconomic status and measures of health have led some experts to advocate policies to improve the status of those in the lower socioeconomic groups. But effective policies require a clear understanding of the reasons why socioeconomic status is correlated with health. Education, occupation, and income are components of socioeconomics with different implications for intervention. This study suggests that the correlations between socioeconomic status and body mass are largely due to education and not occupation or income. Since the data used are cross sectional, we cannot conclude that education results in high or low body mass. Nevertheless, future researchers interested in understanding the impact of socioeconomic status on obesity may want to direct greater attention to education rather than either occupation or income.

The authors would like to thank John Oehlert, Lisa Cendejas, and Mary Peterson for research and typing assistance.

1 Hubert HB, Fienleib N, McNamara P, Castelli WP. Obesity as an independent risk factor for cardiovascular disease: as an independent risk factor for cardiovascular disease: a twenty-six year follow-up of participants in the
Framingham Heart Study. Circulation 1983; 67: 968-77.

2 US National Center for Health Statistics. Health Um National Center for Health Statistics. Health
ims of obesity. National Institutes of Health implications of obesity. National Institutes of Health American College of Physicians, 1985.

3 Davis M, Ettinger WH, Neuhaus JM, Hansk WW. Sex differences in osteoarthritis of the knee: the role of obesity Am F Epidemiol 1988; 127: 1019-30.

4 Garn SM, Bailey SM, Cole PE, Higgins ITT. Level of education, level of income, and level of fatness in adults. $A m$ f Clin Nutr 1977; 30: 721-5.

5 Ross CE, Mirowsky J. Social epidemiology of overweight: a substantive and methodological investigation. F Health Soc Behav 1983; 24: 288-98.

6 Jeffrey RW, Folsom AR, Luepker RV, et al. Prevalence of overweight and weight loss behaviour in a metropolitan adult population: the Minnesota Heart Survey experience. Am $\mathcal{F}$ Public Health 1984; 74: 349-52.

7 Kannel WB. Health and obesity : an overview. In: Conn HL, DeFelice EA, Kue P, eds. Health and obesity. New HL, DeFelice EA, Kue P, eds.
York: Raven Press, 1983: 1-19.

8 Sobal J, Stunkard AJ. Socioeconomic status and obesity: a review of the literature. Psychol Bull 1989; 105: 260-75.

9 Flegal KM, Harlan WR, Landis JR. Secular trends in body mass index and skinfold thickness with socioeconomic factors in young adult women. Am $\mathcal{F}$ Clin Nutr 1988; 48 : $535-43$

10 Kahn HS, Williamson DF, Stevens JA. Race and weight change in US women: the roles of socioeconomic and marital status. Am F Public Health 1991; 81: 319-23.

11 Grossman $M$. The correlation between health and schooling. In: Terleckyj N, ed. Household production and consumption. New York: National Bureau of Economic Research, Columbia University Press, 1975: 147-223.

12 Berger MC, Leigh JP. Schooling, self-selection, and health. f Hum Resources 1989; 24: 433-55.

13 Feldstein PJ. Health care economics. New York: John Wiley and Sons, 1979. 
14 Miller HW. Plan and operation of the health and nutrition examination survey. Hyattsville, MD: National Center for Health Statistics, 1979; DHEW Publication No. (PHS) 791310 (Vital Health and Statitics Series 1, No. 10A).

15 Williams DR. Socioeconomic differentials in health: a review and redirection. Soc Psychol $Q 1990 ; 53.81-99$.

16 Leigh JP. Occupation and coronary heart disease: schooling as a confounder. $\mathcal{F} A M A$ 1988; 259: 157-8.

17 Kaufman BE. The economics of labor markets and labor Kaufman BE. The economics of labor markets and
relations. San Francisco, CA: Oryden Press, 1989.

relations. San Francisco, CA: Oryden Press, 1989.
18 Kennedy P. A guide to econometrics, 2nd ed. Cambridge, MA: MIT Press, 1985.

19 Moulton BR. Random group effects and the precision of regression estimates. $\mathcal{F}$ Econometrics 1986 ; 32: 385-7.

20 Fuller WA, Kennedy W, Schnell D, et al. PCCARP. Iowa: Iowa State University Statistical Laboratory, June 1989.

21 Leigh JP. Direct and indirect effects of education on health. Soc Sci Med 1983; 27: 227-34.
22 Fuchs VR. Economics, health, and post-industrial society. Milbank Mem Fund $Q$ 1979; 57: 153-82.

23 Leigh JP. Schooling and seat belt use. South Econ f 1990; 57 199-208.

24 Grossman M, Joyce TI. Socioeconomic status and health: a personal research perspective. In: Bunker JP, Bomby DS, Kehrer BH, eds. Pathways to health: the role of social factors. Menlo Park, CA: The Henry J Kaiser Family Foundation, 1989.

25 Pincus T, Callahan LF, Burkhauser RV. Most chronic diseases are reported more frequently by individuals with fewer than 12 years of formal education in the age 18-64 US fewer than 12 years of formal education in the

population. $\mathcal{f}$ Chron Dis $1987 ; 40: 865-74$.
26 Deyo RA, Diehl AK. Psychosocial predictors of disability in patients with low back pain. $\mathcal{F}$ Rheumatol 1988; 15: 1557-64. 27 Callahan LF, Brooks RH, Pincus T. Further analysis of learned helplessness in rheumatoid arthritis using a Rheumatology Attributes index. $\mathcal{F}$ Rheumatol 1988; 15 : 418-26.

\section{SANITARY SUPERVISION}

These endeavours to increase the salubrity of town-life by law, are not only open to the criticism that the natural forces already at work render them unnecessary, and to the additional criticism that some of the things strained after are impossible of legislative achievement, but it must further be observed, that even the desiderata which acts of parliament will reach, can be so reached only through very faulty instrumentalities. It is, in this case, as in many others, the peculiarity of what are oddly styled "practical measures", that they supersede agencies which are answering well by agencies which are not likely to answer well. Here is a heavy charge of inefficiency brought against the drains, cesspools, stink-traps, \&c., of England in general, and London in particular. The evidence is voluminous and conclusive, and by common consent a verdict of proven is returned. Citizens look grave and determine to petition parliament about it. Parliament promises to consider the matter; and after the usual amount of debate, says- "Let there be a Board of Health". Whereupon petitioners rub their hands, and look out for great things. They have unbounded simplicity - these good citizens. Legislation may disappoint them fifty times running, without at all shaking their faith in its efficiency. They hoped that Church abuses would be rectified by the Ecclesiastical Commission: the poor curates can say whether that hope has been realized. Backed by an act of parliament, the Poor-Law Commissioners were to have eradicated able-bodied pauperism: yet, until checked by the recent prosperity, the poors'-rates have been rapidly rising to their old level. The New Building Act was to have given the people of London better homes; whereas, as we lately saw, it has made worse the homes that most wanted improving. Men were sanguine of reforming criminals by the silent system, or the separate system; but, if we are to judge by the disputes of their respective advocates, neither of these plans is very successful. Pauper children were to have been made into good citizens by industrial education; from all quarters, however, come statements that a very large percentage of them get into gaol, or become prostitutes, or return to the workhouse. The measures enjoined by the Vaccination Act of 1840 were to have exterminated small-pox; yet the Registrar-General's reports show that the deaths from small-pox have been increasing. And thus does year after year add to those abortive schemes, of which so many have been quoted. Yet scarcely a doubt seems to arise, respecting the competency of legislators to do what they profess. From the times when they tried to fix the value of money down to our own day, when they have just abandoned the attempt to fix the price of corn, statesmen have been undertaking all kinds of things, from regulating the cut of boot-toes, up to preparing people for Heaven; and have been constantly failing, or producing widely-different results from those intended. Nevertheless such inexhaustible faith have men, that, although they see this, and although they are daily hearing of imbecilities in public departments-of Admiralty Boards that squander three millions a year in building bad ships and breaking them up again—of Woods and Forests Commissioners who do not even know the rental of the estates they manage- of bungling excise-chemists who commit their chiefs to losing prosecutions, for which compensation has to be made-yet government needs but to announce another plausible project, and men straightway hurrah, and throw up their caps, in the full expectation of getting all that is promised.

Social Statics: or the conditions essential to human happiness specified, and the first of them developed by Herbert Spencer, 1851 